\title{
NeW WheELSET DESIGN FOR RAIL TRANSPORT
}

\author{
Valeriy Shiler, Alexander Shiler, Ilham Galiev
}
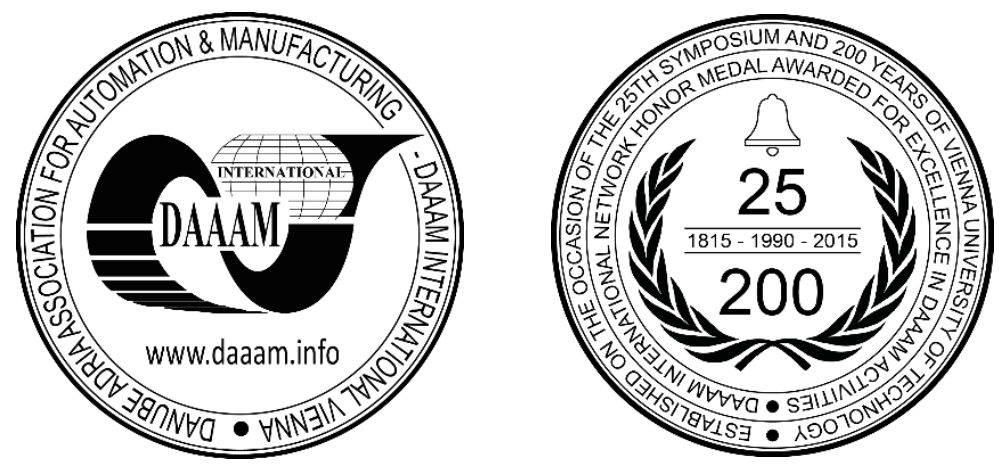

This Publication has to be referred as: Shiler, V[aleriy]; Shiler, A[lexander] \& Galiev, I[lkham] (2016). New Wheelset Design for Rail Transport, Proceedings of the 27th DAAAM International Symposium, pp.0896-0900, B. Katalinic (Ed.), Published by DAAAM International, ISBN 978-3-902734-08-2, ISSN 1726-9679, Vienna, Austria DOI: $10.2507 / 27$ th.daaam.proceedings.129

\begin{abstract}
Economic efficiency and competitiveness of rail transport depends mainly on the reducing the level of the dynamic interaction between wheel and rail. This paper presents a new technical solution for the wheelset in the form of a block design of the wheels. Analysis of the motion path of contact points was carried out in the system «wheelset - rail track». The paper evaluates the stress state of the block construction elements of the wheelset and shows the results of comparative theoretical and prototype tests of the block and standard wheelsets.
\end{abstract}

Keywords: block wheel; wheelset; independent rotation; motion path; contact; rail.

\section{Introduction}

The main disadvantages of a standard wheelset are significant unsprung weight $(1500 \div 5000 \mathrm{~kg})$ acting on the contact wheel-to-rail surfaces and the rigid connections concerning the coordinate rotation between points on the surface of wheels between the coordinate points of rotation of the wheel contacting with surfaces of rails [1,2]. During the moving all points on the surfaces of wheels rotate at the same angular speed and wheels pass a different path length on the rails due to the presence of the inevitable difference of diameters of running surfaces. Such motion is accompanied by a «parasitic» wheel sliding on the rails and within the gap with rail track the wheelset moves in a winding path (continuous process of searching for equality of rolling circles diameters) - self-oscillation mode.

The winding motion occurs by energy of a forward motion, increasing resistance to its movement. But such a motion path for the standard wheelset is a blessing since the wheel flange contacts with the rail not constantly but only in $20 \div$ $30 \mathrm{~m}$ (wavelength of the winding motion).

Search of the wheelset design without disadvantages inherent in standard wheelset are conducted for a long time. Currently, it has accumulated more than 60 variants of technical solutions. The main features of these variants: independent rotation of the wheels in the wheelset, tire springing relative to wheel centre, wheels mounting at an angle relative to the vertical axis, division of the rigid axle of the wheelset on two parts connected by an elastic or freewheeling clutch [3]. 


\section{Block design of the wheelset}

Based on the analysis of numerous wheelsets designs the authors have proposed new technical solution of wheelset in which the wheels have a block design (Fig. 1) [4]. Block wheel consist of supporting and guiding 3 wheels. Rim of the guiding wheel has a standard shape of flange on the perimeter. The guiding wheel 3 is tightly fixed to the wheelset axle 8 and it perceives the horizontal guiding forces from side surface of rail. Supporting wheel consists of wheel centre 5, rubber pad 11 and flexible tire 1 and it is mounted on wheelset axle 8 by a pair of wheel bearing 13. Wheelset axle is mounted on the wheel bearing 9 of journal box and it transmits a vertical load through a wheel centre 5, elastic medium 11 and flexible tire 1 , that rolls along a running surface of rail.

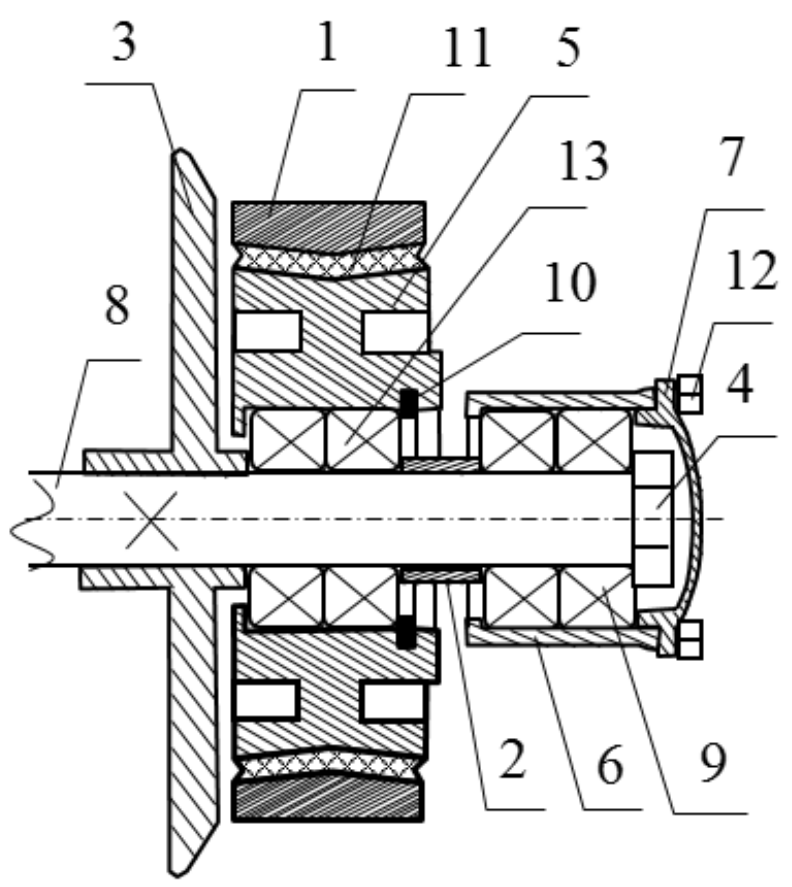

Fig. 1. Block wheel of a wheelset of a rail vehicle

Figure 2 shows the kinematic scheme of mechanical linkages on the rotation coordinate between the elements of the block design of the wheelset. In the mechanical system of «block wheelset - track», as in «standard wheelset - track», there are three mechanical loop with the same the basic sizes. In the system «block wheelset - track» the first (I) and second (II) mechanical loops are open (Fig. 2b.) due to the wheel centres mounting on bearings 13 (Fig. 1). The third loop (III) is formed by two guiding wheels 3 (fig. 1 and 2) tightly fixed to the wheelset axle. Only one of two guiding wheels can be in contact with the rail since the guaranteed open gap equal to $0.01 \mathrm{~m}$ (Fig. $2 \mathrm{~b}$ and $2 \mathrm{c}$ ) is provided between the wheel and rail gauges. Therefore, at any position of the wheelset in the rail gauge in the system «block wheelset - track» all mechanical loops (I, II and III) are open (Fig. 2b and 2c.). It allows to create the design of block wheelset without mechanism of the winding motion and eliminate such deficiencies as the impact of the difference in the wheel diameter on the position of the wheelset to the rail gauge, «parasitic» wheel slippage on rails during the forward motion in direct and curved parts of railway track, significantly reduce the unsprung weight in the system «wheelset - rail gauge».
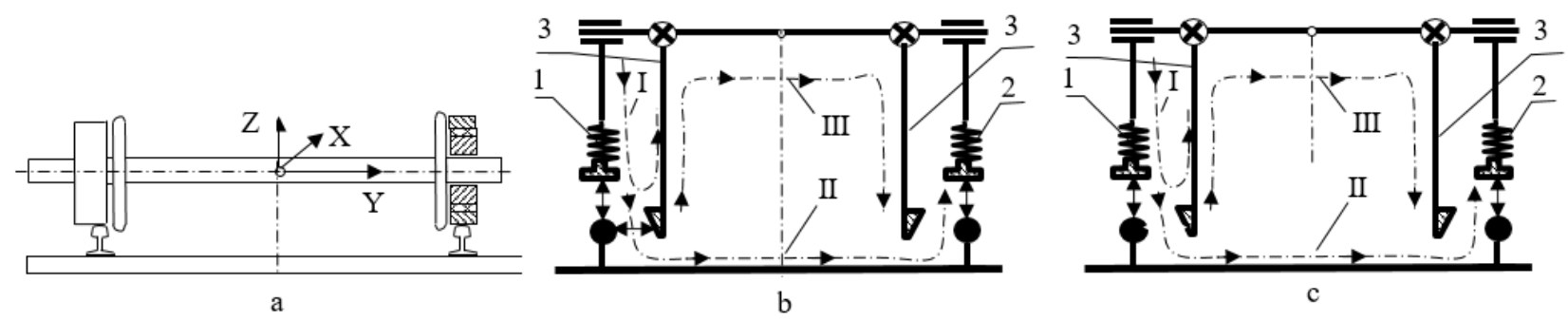

Fig. 2. Schemes of the mechanical loops of the system «block wheelset - rail gauge»

a) kinematic scheme of the block design of the wheelset;

b) mechanical loops when the flange of the guiding wheel contacts with a rail;

c) mechanical loops when the contact between flange of the guiding and rail is absent. 


\section{Analysis of motion trajectories of contacts points in the system «wheelset - rail gauge»}

Figure 3 shows the motion trajectory of the contact points of the running surfaces of block and standard wheels in contact with the surfaces of a rail head, where $\mathrm{K}$ is contact point of running surface of flexible tire and standard wheels, $\mathrm{B}$ is flange of standard wheel and D is guiding wheel block design of wheelset. Trajectory of point $(\mathrm{K})$ is an ordinary cycloid (Fig. 3, Line 1). The contact point (D) of the guiding wheel moves along the trajectory of ordinary cycloid (Fig. 3 , Line 3), provided that the angle of attack on the rail is zero. As is known, the main feature of the ordinary cycloid is the equality of distance traversed by center of the generating circle $\left(\mathrm{O}_{\mathrm{k}}\right)$ and its expanded length which corresponds to the wheel motion without slippage.

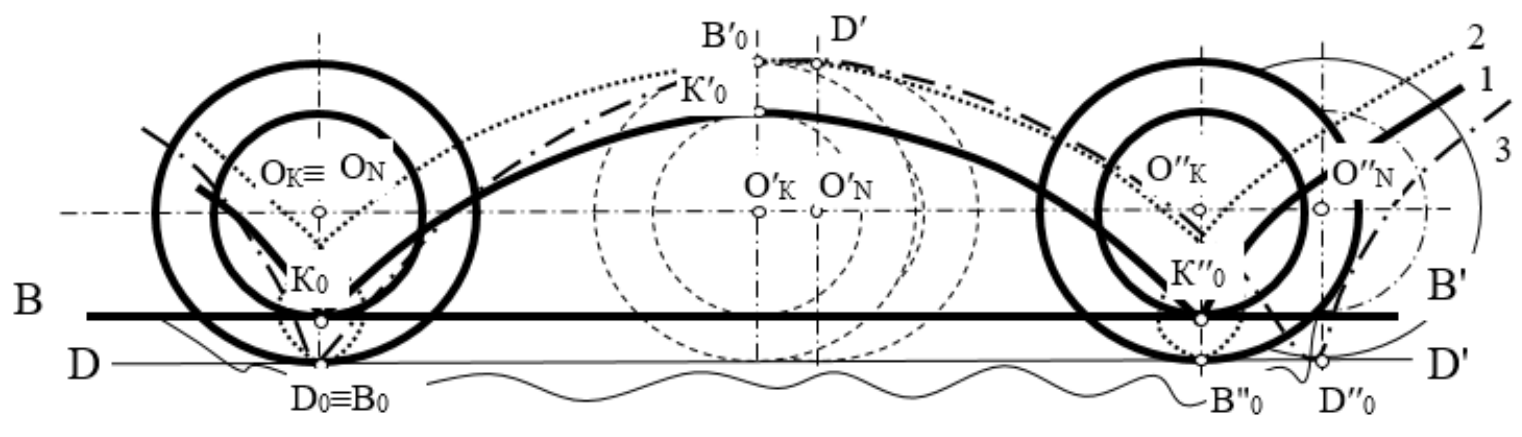

Fig. 3. The motion trajectory of the contact points of the running surfaces of block and standard wheels

Line 1 is trajectory of the point $\left(\mathrm{K}_{0}\right)$ of the rolling surface of wheels (the curve $\mathrm{K}_{0} \mathrm{~K}_{0}{ }^{\prime} \mathrm{K}_{0}{ }^{\prime}$ is an ordinary cycloid); Line 2 is trajectory of the point $\left(\mathrm{B}_{0}\right)$ of the side surface of the standard wheel flange (the curve $\mathrm{B}_{0} \mathrm{~B}_{0}{ }^{\prime} \mathrm{B}_{0}{ }^{\prime \prime}$ is an elongated cycloid);

Line 3 is trajectory of the contact point $\left(\mathrm{D}_{0}\right)$ of the side surface of the guiding wheel flange (the curve $\mathrm{D}_{0} \mathrm{D}_{0}{ }^{\prime} \mathrm{D}_{0}$ " is an ordinary cycloid).

The trajectory of the contact point (B) of the standard wheelset flange looks like an elongated cycloid (Fig. 3 and 4 , line 2). The presence of a loop of elongated cycloid indicates a repetition of the traversed distance and consequently a «parasitic» slippage of standard wheel flange along the side surface of the rail head.

Instantaneous radius $\left(r_{D_{1}}\right)$ of point of rotation $\mathrm{D}_{1}$ relative to the instantaneous center $\left(\mathrm{K}_{0}\right)$ is determined by the equation:

$$
r_{D_{1}}=\sqrt{t^{2}+\lambda_{p}^{2}}
$$

where $t$ is a height of the contact point location $\mathrm{D}_{0}$ relative to the rolling surface of the rail $\left(\mathrm{K}_{0}\right),(t=10 \mathrm{~mm}) . \lambda_{p}^{2}$ is a value of «race» of the contact point $\mathrm{D}_{1}$ relative to the vertical axis of the wheels $\left(\mathrm{D}_{0} \mathrm{O}_{0}\right)$ and determined by the formula [3]:

$$
\lambda_{p}=\left(r_{K}+t\right) \cdot \operatorname{tg}(\alpha+\gamma) \cdot \operatorname{tg}(\tau)
$$

where $\alpha$ is a angle of attack of the wheel flange on the rail;

$\tau$ is an angle of slope of the side surface of the flange to the horizon;

$\gamma$ is an angle of withdrawal of the rail gauge.

The length of sliding distance of the contact point of the standard flange $\left(D_{1}\right)$ along the rail head in one wheel revolution with regard to the equation (1) has the following correspondence:

$$
L_{D_{1}}=2 \cdot \pi \cdot r_{D_{1}}=2 \cdot \pi \cdot \sqrt{t^{2}+\lambda_{p}^{2}}
$$

When the standard wheel flange steps on the rail at an angle the contact point (Fig. 4) is displaced relative to the vertical axis of the wheel on the value of the «race» $\left(\lambda_{p}\right)$ and is located at a point $\left(D_{1}\right)$. In this case the radius of elongated cycloid loop increases and thereby the length of sliding distance of the flange side surface on the side surface.

When the guiding wheel flange of block wheelset steps on the rail at an angle the contact point (Fig. 4) is also displaced relative to the vertical axis of the wheel to the same value of the «race» $\left(\lambda_{p}\right)$ and is located at a point $\left(\mathrm{D}_{1}\right)$. But the end of the generatrix $\mathrm{O}_{0} \mathrm{D}_{1}$ (point $\mathrm{D}_{1}$ ) describes the curved trajectory $\mathrm{D}_{1} \mathrm{D}_{2} \mathrm{D}_{1}$, which corresponds to the determinant of the irregular curve, known as «Conchoid of Nicomedes». When the guiding wheel moves translationally the generatrix $\mathrm{O}_{0} \mathrm{D}_{1}$ 
slides in point $\mathrm{D}_{1}$ (instantaneous center of rotation) on the side surface of the rail head in two directions: the rotation relative to the point D1 (spin-torque) and the linear movement along a generator $\mathrm{O}_{0} \mathrm{D}_{1}$. The rotation of the generatrix $\mathrm{O}_{0} \mathrm{D}_{1}$ in point $\mathrm{D}_{1}$ was not considered in the calculation of the value of the length of sliding distance of guiding wheel flange on the rail head because the smallness of the area of contact ( $D_{1}$ point).

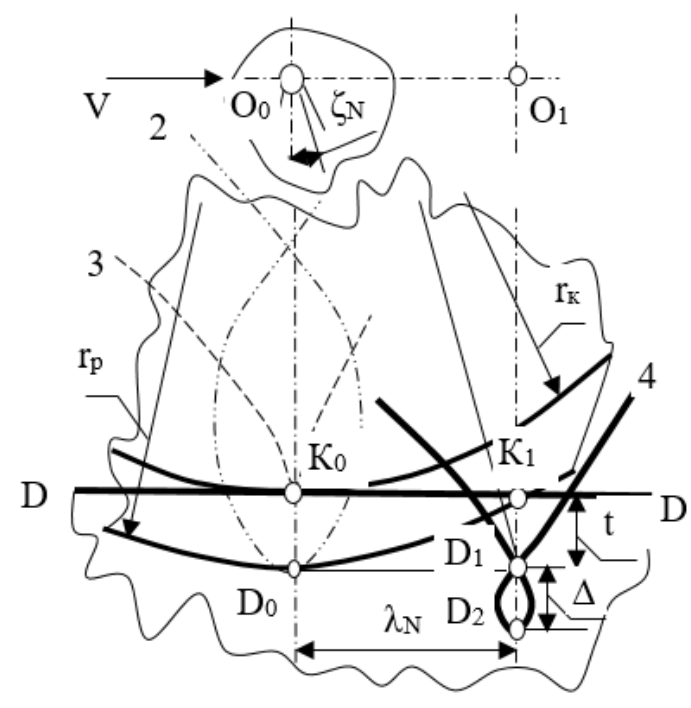

Fig. 4. Trajectory of the contact point of flange surface of guiding wheel with the rail head

The value of the length of sliding is determined from the geometric relationship in a right triangle:

$$
\Delta=\sqrt{\left(r_{k}+t\right)^{2}+\lambda_{p}^{2}}-\left(r_{k}+t\right)
$$

where $r_{k}$ is a radius of the running surface of the supporting wheel, $\mathrm{mm}$;

Calculation results of the length of sliding distance of guiding wheel flange and standard wheel flange are fulfilled using equations 3 and 4, and finalized to one wheel rotation (Fig. 5, curves 1 and 2 respectively).

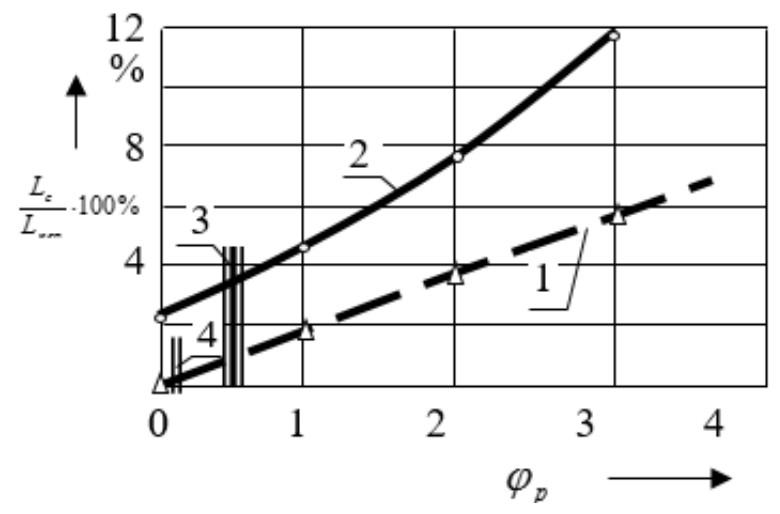

Fig. 5. Dependence of the sliding length of flanges along the rail head on the angle of attack of the wheels on the rails:

1- standard wheel; 2 - guiding wheel of block design wheelset.

The maximum possible value of the angle of attack of the flanges on the rail:

3 - standard wheel; 4 - guiding wheel of the block design of wheelset.

According to the graph (Fig. 5), the main advantage of the block design of wheels is that at the zero value angle of attack of the guiding wheel on the rail the flange rolls along the side surface of the rail head without sliding in resistance to rolling regime. When the guiding wheel steps on the rail at an angle $(\alpha)$ the length of «parasitic» sliding distance of the flange on the side surface of trail significantly less (in 2 - 8 times) as compared to standard wheel flange. According to the results of full-scale study and theoretical calculations was determined that the at a straight section of the distance for the standard wheelset the maximum value of the angle of attack of flange is $0,5^{\circ}[1,5]$, the calculated value for the block design of wheelset is $0,2^{\circ}$ (Fig. 5, lines 3 and 4 respectively). 


\section{Stress state of the elements of the block design of wheelset}

If the independent rotation of the supporting and guiding wheels in block wheelset is absent the «parasitic» sliding of wheels on the rails which form the tangential stresses at the contact point of wheels and rails in the elements of standard design and the twisting moment of force in the wheel axle. The cylindrical surface of the flexible flange (Fig. 6) has a constant one-point contact $\left(\mathrm{K}_{0} \equiv \mathrm{K}_{\mathrm{p}}\right)$ in the central part of the rail head surface at any position of the wheelset relative to the rail gauge and the level of excessive wear of the contacting surfaces. Therefore, the contact stress zone of normal reaction forces of the supporting and guiding wheels are located at a substantial distance from each other that provides their equal distribution across the perimeter of the rail head and wheel surfaces. It reduces significantly the levels of the contact stresses and, accordingly, a fatigue damage of metal of the block wheel and rail.

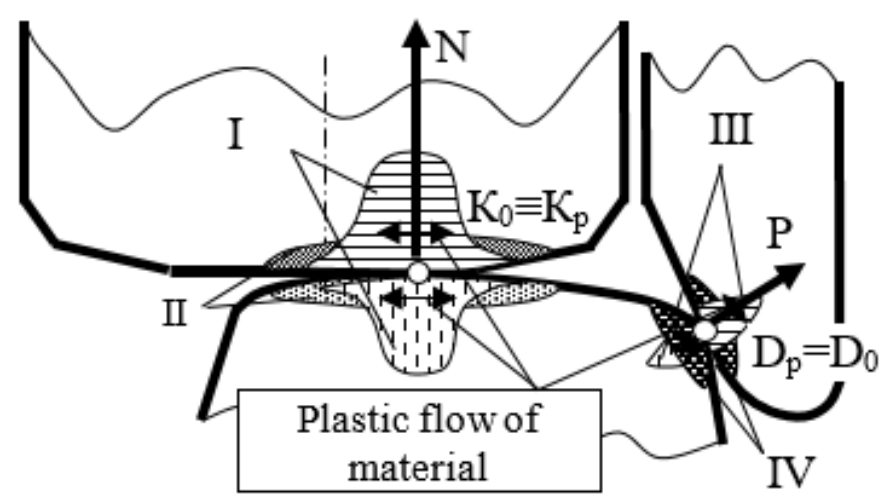

Fig. 6. Model of metal stress state of the rail and the wheel of the block design under normal (I and III) and worn-out (II and IV) profiles of running surfaces of the support and guiding wheels

\section{The results of comparative tests}

The results of comparative theoretical, prototype and bench tests of two wheelsets variants (block wheel and standard wheel) show the following:

- in a range of accommodate speeds up to $100 \mathrm{~km} / \mathrm{h}$ the resistance to motion of block wheelset is less in $1.5-2$ times as compared with the standard design (in direct and curved sections of distance);

- motion trajectory of the block wheelset in a horizontal plane depends only on a relative position of wheelset in a bogie. Irregularities of the rail gauge in the plan do not influence a horizontal dynamics of block wheelset;

- in a biaxial bogie when the rail flange touches the first block wheelset on the motion, the second block wheelset rolls on a tractrix trajectory (line of least resistance) in the direction of the guiding rail till establish contact with it. As a result, in the curved sections of the distance the bogie with the block wheelset automatically takes a chordal position in the whole speed range of the rolling stock motion;

- setting of block wheelset into existing bogies design of passenger and freight wagons allows to essentially increase an axial load and motion speed under the condition the permissible values of stresses in the elements of rails and wheelsets designs.

On the basis of executed researches the following conclusions were reached:

New technical solution of a wheelset design in which there are no mechanical closed loops, that allow to eliminate a parasitic slippage of wheels on rails in the system «wheelset - rail». It leads to a significant reduction in the intensity of the formation of such types of wear and defects as clearance under flange, side undercut of flange and slid flat. In turn, this allow to increase the run between the rolling stock maintenance up to 1 million kilometres.

\section{References}

[1] Pankin, I. (1992). The Nature of the Solids Friction Force, Railway Transport, Vol. 7, pp. 52-56

[2] Improving Communication between the Rolling Stock and Track, Railways of the World, No. 2, 2003, pp. 48-53

[3] W. J. Harris, S. M. Zakharov, J. Landgren, Ch. Turne, and V. Ebersen, Generalization of the World Experience of Heavy-Weight Railway Traffic: The Problems of Wheel-Rail Interaction (Intekst, Moscow, 2002) [in Russian].

[4] Galiev, I., Shiler, V., Gorbunov, P., Kychakov, K., Nikolaev, V., Talovsky, D. The Transverse Profile of Flange (patent), Patent №2378127 Russian Federation, №2008131365 at the request from 10.12.2009, pp. 1-10

[5] Kamaev, A.; Soroka, M.; Kolpakov, F. (1971). Impact on the Tracks into the Circular Curve Bogies with Freely Rotating Wheels, Dynamics of Railway Rolling Stock, Bryansk Institute of Transport Engineering, Vol. 23, pp. 156159 